Proc. of the International Conference on Mechanochemistry and Mechanical Alloying, Kraków, Poland, June 22-26, 2014

\title{
Illustration of Selected Functional Inorganic Materials Fabricated by Mechanochemical Approaches
}

\author{
K. WiECZOREK-CIUROWA* \\ Faculty of Chemical Engineering and Technology, Cracow University of Technology, \\ Warszawska 24, 31-155 Kraków, Poland
}

\begin{abstract}
The paper highlights versatility of high-energy milling in engineering of different functional materials using three approaches which give the benefits as green processes. They are: direct mechanosyntheses, modification of properties and activation of solids by co-milling procedures. The examples are presented.
\end{abstract}

DOI: 10.12693/APhysPolA.126.1049

PACS: 81.20.Ev, 82.35.Pq, 77.22.Gm

In mechanochemistry, there are various approaches that benefit the engineering of solids and, additionally, they can be considered as green processes [1-7]. These are mainly three categories:

\#A Direct mechanosyntheses between the reagents depending upon the nature of the desired product with the use of: a) SHS reactions, b) acid-base properties of oxides;

\#B Modification of properties via high-energy milling by: a) appropriate substitution of various cations in sublattices of complex oxides e.g. with perovskite structure, b) the use of the presence of impurities from the reactor and balls in order to improve the usable features of a product;

\#C Activation of solids by co-milling process by: a) supporting of catalytic precursor on carrier, b and c) mechanical treatment of reactants before or after conventional synthesis process of catalysts.

The practical examples are described below.

\section{\#A1 - in situ mechanosyntheses of nanocomposite powders}

In situ mechanosyntheses of nanocomposite powders such as metal matrix composites (MMCs) via selfpropagating high-temperature synthesis (SHS) with the kinetics of stepwise product formation [4] using the transition metals (e.g. $\mathrm{Cu}, \mathrm{Ni}$ ) hydroxocarbonates and active metals (e.g. $\mathrm{Al}, \mathrm{Zn}$ ) combines the good properties of intermetallics $\left(\mathrm{Cu}_{9} \mathrm{Al}_{4}, \mathrm{CuAl}_{2}\right.$ and $\mathrm{NiAl}, \mathrm{Ni}_{3} \mathrm{Al}$, respectively, as well as solid solutions - $\mathrm{Cu}(\mathrm{Al})$ ) with the advantages of ceramics $\left(\mathrm{Al}_{2} \mathrm{O}_{3}\right)$. The benefit of this synthesis over others results in a more homogeneous, thermodynamically stable product. It is very useful if the progress of SHS reactions can be monitored using gastemperature and pressure system (GTM) during milling (Figs. 1, 2).

The consolidation of the powders - the high compression method on a hot (HP-HT) or the pulse-plasma

* corresponding author; e-mail: kwc@pk.edu.pl

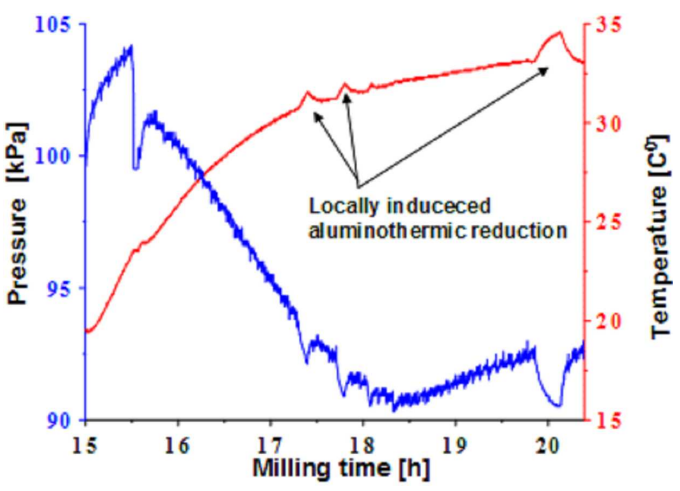

Fig. 1. The course of stepwise product formation during final step of metalothermic reaction in $\mathrm{Cu}_{2}(\mathrm{OH})_{2} \mathrm{CO}_{3}-\mathrm{Al}$ mixture (planetary ball mill Fritsch GmbH Pulverisette 6) [8].

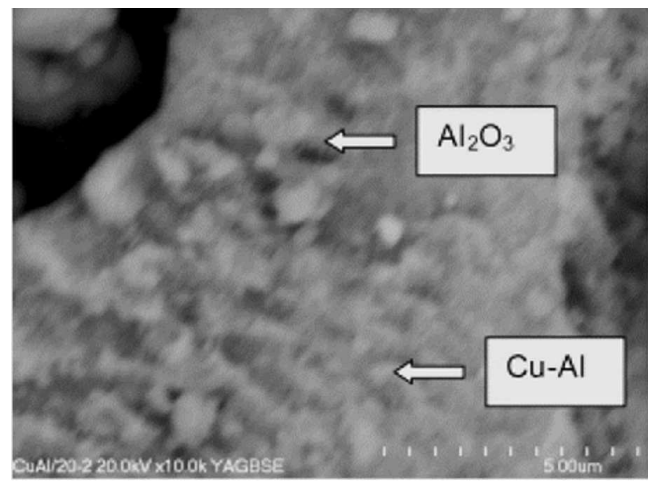

Fig. 2. SEM microphotograph (BSE image) illustrating a high level of structure homogeneity in a $\mathrm{Cu}_{-}$ $\mathrm{Al} / \mathrm{Al}_{2} \mathrm{O}_{3}$ composite powder following aluminothermic reaction at the final stage of milling; the dark spots correspond to $\mathrm{Al}_{2} \mathrm{O}_{3}$, the brighter grey ones to $\mathrm{Cu}-\mathrm{Al}$ intermetallics [8].

sintering (PPS) provides composites characterized by a high-specific strength, good wear resistance and excellent properties at high temperatures over conventional alloys. These products have potential of lightweight structural materials used as engine parts in automobile and aerospace industry [9]. 
It is also worthwhile to add that $\mathrm{Cu}-\mathrm{Al}_{2} \mathrm{O}_{3}$ composite powder (catalyst-carrier system) obtained as described above is catalytically active towards hydrogen production in methanol stream reforming (SRM) process. Then the specific surface area does not determine the catalytic activity but active centers formed during mechanical treatment [10].

$$
\begin{gathered}
\text { \#A2 - mechanosynthesis of ceramic-metal } \\
\text { nanopowders as fillers to polymer-ceramics/metal } \\
\text { nanomicrocomposites for tribology }
\end{gathered}
$$

Mechanical treatment of the reactants, $\mathrm{CuO}$ and $\mathrm{Fe}_{3} \mathrm{Si}$ leads to the following reactions:

$$
\begin{aligned}
& 2 \mathrm{CuO}+\mathrm{Si} \rightarrow 2 \mathrm{Cu}+\mathrm{SiO}_{2}, \quad \Delta H=-596 \mathrm{~kJ} / \mathrm{mol}, \\
& 4 \mathrm{CuO}+3 \mathrm{Fe} \rightarrow 4 \mathrm{Cu}+\mathrm{Fe}_{3} \mathrm{O}_{4}, \quad \Delta H=-488 \mathrm{~kJ} / \mathrm{mol} .
\end{aligned}
$$

The formed $\mathrm{Cu} / \mathrm{SiO}_{2}-\mathrm{Fe}_{x} \mathrm{O}_{y}$ powders can be applied as fillers of epoxy or phenol-formaldehyde matrix (see Fig. 3). Tribological properties (wear and friction) of such polymer-metal/ceramics composites indicate on their applying as components of brake systems, bearings or clutches [11-13].

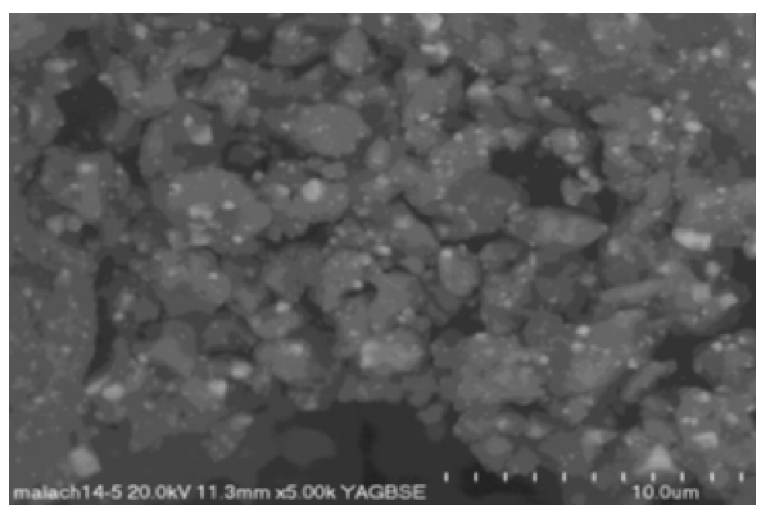

Fig. 3. SEM microphotograph (BSE image) of $\mathrm{Cu}^{0} / \mathrm{Fe}_{x} \mathrm{O}_{y}-\mathrm{SiO}_{2}$ nanocomposite powder; white spots $\mathrm{Cu}^{0}[11]$.

\section{\#A3 - direct mechanosyntheses of bioceramic materials (hydroxoapatite, HAp) using acid-base properties of reactants}

The crystalline $\mathrm{Ca}_{10}\left(\mathrm{PO}_{4}\right)_{6}(\mathrm{OH})_{2}$ synthesis and/or its mechanical properties modification (the strength and fracture toughness) via the high-energy ball milling were investigated [14]. Complexity of synthesis results in the various phase formation in the $\mathrm{CaO}-\mathrm{P}_{2} \mathrm{O}_{5}-\left(\mathrm{H}_{2} \mathrm{O}\right)$ system which is greatly affected by a slight difference in the process conditions. The interaction between the initial components from this system in water medium during mechanical treatment followed by calcination at $700-900{ }^{\circ} \mathrm{C}$ for 1 to $2 \mathrm{~h}$ provides crystalline hydroxoapatite product. For instance, it is also possible to modify HAp properties by doping or substitution of $\mathrm{Ca}^{2+}$ by zirconium impurities from balls and milling reactor.

$$
\text { \#A4 - examples of high-energy ball milling of oxides }
$$

High-energy ball milling of oxides (with acid-base properties) such as perovskites $\mathrm{ATiO}_{3}$ (where $\mathrm{A}=\mathrm{Ba}^{2+} \mathrm{Sr}^{2+}$, $\mathrm{Ca}^{2+}$ ), e.g. $\mathrm{CaO}+\mathrm{TiO}_{2} \rightarrow \mathrm{CaTiO}_{3}$ are important compounds for electric charge storage applications [15, 16].

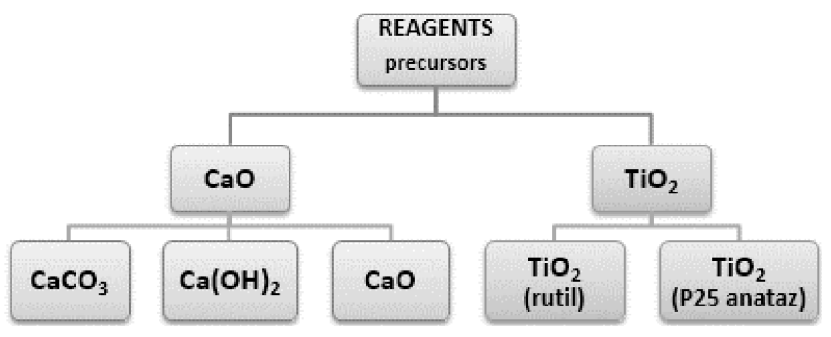

Fig. 4. Various of oxides' precursors to syntheses of complex oxides $\left(\mathrm{ATiO}_{3}\right)$.

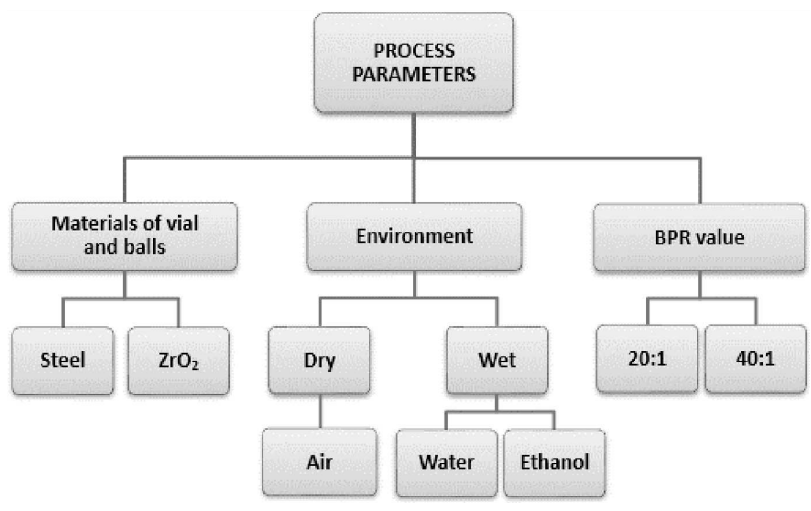

Fig. 5. Various milling conditions in mechanochemical syntheses of $\mathrm{ATiO}_{3}$.

Properties of ceramic materials are sensitive to structural parameters, which in turn strongly depend on the method of preparation. Our research aimed at applying the various oxide precursors (Fig. 4) as well as various milling conditions (Fig. 5). It would mean optimization of parameters of the process.

$\# B 1-$ modification of dielectrics by substitution of
various cations $\left(\mathrm{Cu}^{2+}, \mathrm{Ca}^{2+}, \mathrm{Sr}^{2+}, \mathrm{V}^{5+}, \mathrm{Nb}^{5+}\right)$ in
sublattices of complex oxides with perovskite structure $\left(\mathrm{ATiO}_{3}\right)$

With the miniaturization of electronic devices, materials exhibiting a high value of dielectric permittivity $\left(\varepsilon^{\prime}\right)$ play an increasing importance in the electronics industry [17-19].

Example: Simultaneous synthesis of $\mathrm{CaTiO}_{3}$ and its modification by substitution of calcium and titanium sub-lattice by copper ion

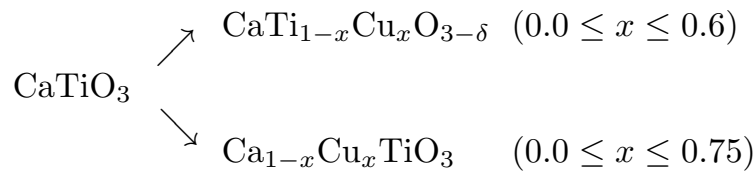


This ternary oxide system $\mathrm{CaO}-\mathrm{TiO}_{2}-\mathrm{CuO}$ presents a high value of dielectric permittivity $\left(\varepsilon^{\prime}\right)$ and low dielectric loss $(\tan \delta)$.

Complex systems with perovskite structure oxide, such as $\mathrm{Ca}_{0.25} \mathrm{Cu}_{0.75} \mathrm{TiO}_{3}$ with an unusually high value of dielectric permittivity and its independence of temperature can potentially be used for appropriate material for these applications. Electrical properties of such electroceramics strictly depend on the method of production and the synthesis parameters.

The original papers $[16,20]$ present the synthesis of calcium titanate as well as its modification by substitution of copper ions in calcium subnet $\left(\mathrm{Ca}_{1-x} \mathrm{Cu}_{x} \mathrm{TiO}_{3}\right.$, $0 \leq x \leq 0.75)$ and titanium $\left(\mathrm{CaTi}_{1-x} \mathrm{Cu}_{x} \mathrm{O}_{3}, 0 \leq x \leq\right.$ $0.4)$ by means of high energy milling. This method is an alternative to conventional ceramic manufacturing techniques, such as high- temperature solid-state synthesis, sol-gel, co-precipitation or hydrothermal methods.

Measurements of dielectric spectroscopy were performed in the frequency domain $20 \mathrm{~Hz} \div 1 \mathrm{MHz}$ using the Agilent4284 LCR meter and a temperature control system Quatro Krio 4.0.

\#B2 - the presence of $\mathrm{Fe}^{0}, \mathrm{ZrO}_{2}, \mathrm{Si}_{3} \mathrm{~N}_{4}$ - impurities from the reactor and balls in $\mathrm{ATiO}_{3}\left(\mathrm{~A}=\mathrm{Ba}^{2+}, \mathrm{Ca}^{2+}\right)$

Impurities in the products - exfoliated from grinding media are difficult to remove [20-22]. However, it might be used to control the electrical properties of ceramics as is seen in Figs. 6-7. Examples manufacturing of new materials on the mechanochemical way are mainly an alternative method to high-temperature treatment of solids, therefore it is necessary to present it for comparison.
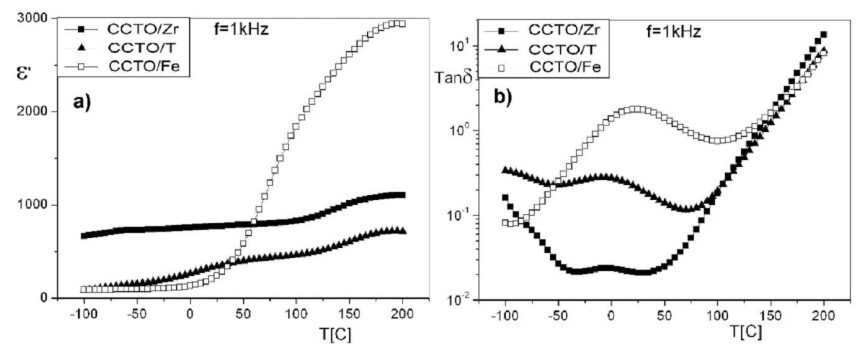

Fig. 6. Temperature relationship of the real component of dielectric permittivity $\left(\varepsilon^{\prime}\right)(\mathrm{a})$ and dielectric loss $(\tan \delta)$ (b) at the field frequency of $1 \mathrm{kHz}$ for $\mathrm{CaCu}_{3} \mathrm{Ti}_{4} \mathrm{O}_{12}$ (CCTO) synthesized mechanochemically (CCTO/Zr and $\mathrm{CCTO} / \mathrm{Fe}$ ) and by high-temperature treatment $(\mathrm{CCTO} / \mathrm{T})[20]$.

The materials synthesized by mechanochemical way are attractive for microelectronic devices because of a high value of dielectric permittivity $\left(\varepsilon^{\prime}\right)$ and low dielectric loss $(\tan \delta)$ in wide useful temperature range.

\section{\#C1 - heterogeneous catalyst-carrier systems' preparation by co-milling}

Traditional methods of catalyst preparation, which are based on precipitation and/or impregnation, are multistep processes. Mechanochemical treatment achieved by
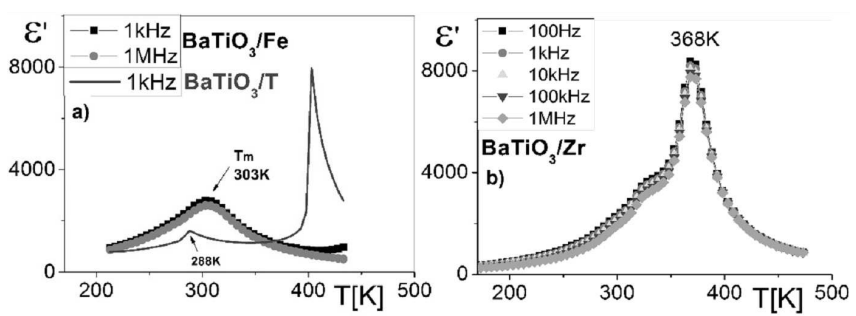

Fig. 7. The temperature dependence of real part of dielectric permittivity $\left(\varepsilon^{\prime}\right)$ at the different frequency field for (a) $\mathrm{BaTiO}_{3} / \mathrm{T}, \mathrm{BaTiO}_{3} / \mathrm{Fe}$, and (b) $\mathrm{BaTiO}_{3} / \mathrm{Zr}$ samples [21].

high-energy ball milling of solid catalytic precursors in a single step reduces this disadvantage. Activation of appropriate selected reactants leads to support of one of them (i.e. with catalytic properties) on the second one. It is useful to remember that the type of synthesis influences the properties of product. Important is the comparison of effects of the catalytic activities with catalyst prepared by conventional way, i.e. by high-temperature treatment. Some examples using mechanical treatment procedure are shown below:

i. Supported vanadia $\left(\mathrm{V}_{2} \mathrm{O}_{5}\right)$ nanolayer on chromia $\left(\mathrm{Cr}_{2} \mathrm{O}_{3}\right)$ is catalytically effective in oxidative dehydrogenation of propane $(\mathrm{ODH})$ because of the reduction of vanadium $(\mathrm{V})[23]$;

ii. Metallic copper supported on boemit (AlOOH) by attrition of $\mathrm{Cu}$-balls is active in methanol steam reforming, SRM, for the hydrogen production [24];

iii. Mechanical treatment of mixture $\mathrm{MoO}_{3}$ and $\mathrm{TiO}_{2}$ allows to support $\mathrm{MoO}_{3}$ on $\mathrm{TiO}_{2}$ giving the $\mathrm{Mo}-\mathrm{Ti}-\mathrm{O}$ catalyst active in direct benzene oxidation by molecular oxygen to phenol [25].

iv. $\mathrm{Cu}_{3} \mathrm{Fe}_{4}\left(\mathrm{VO}_{4}\right)_{6}$ compound formed by mechanical treatment of appropriate metal oxides has better catalytic properties in SRM process than obtained by hightemperature synthesis which is complicated in realization [26-28].

\section{\#C2 - mechanical treatment of reagents before or after the conventional synthesis process of catalysts in ecosystem}

i. $\mathrm{V}-\mathrm{P}-\mathrm{O}$ catalyst for $n$-butane oxidation to maleic anhydride with used of a mechanically pre-treated $\mathrm{V}_{2} \mathrm{O}_{5}$ leads to a change in its morphology and partial reduction of vanadium ions $\left(\mathrm{V}^{+5} / \mathrm{V}^{+4}\right)$ [29]. It gives benefits as follows:

- during production of the catalysts less solvent is needed and less toxic by-products are formed;

- reducing agent is excluded from catalyst synthesis;

- high activity of catalyst reduces the emission of $\mathrm{CO}_{2}$ in maleic anhydride manufacture.

ii. Mechanochemical treatment of the $\mathrm{CuO}$ $(25 \%) / \mathrm{CeO}_{2}$ catalyst prepared by citrate method leads to changes of its surface morphology and increases activity of this catalyst in total oxidation of $\mathrm{C}_{3} \mathrm{H}_{6}, \mathrm{C}_{6} \mathrm{H}_{6}$ and $\mathrm{CO}[29]$. Therefore, $\mathrm{Cu}-\mathrm{Ce}-\mathrm{O}$ catalyst can be used 
for neutralization of $\mathrm{CO}$ and hydrocarbons in industrial gaseous wastes and $\mathrm{CO}$ removal from hydrogen for fuel cell.

High-energy milling processes of the appropriate powders of different systems described in the cited by author papers were performed using two planetary ball mills (Pulverissette 6, Fritsch GmbH and Activator 2S, Novosibirsk Corp.), with different energetics and materials of reactors and balls (e.g. $\mathrm{ZrO}_{2}, \mathrm{Si}_{3} \mathrm{~N}_{4}, \mathrm{WC}$ and steel). The effects of various process parameters and the peculiarities of mechanochemical synthesis in terms of properties of the materials were determined.

The physicochemical properties of milling products have been estimated from the results of X-ray powder diffraction, values of specific surface area and porosity, thermal analysis, scanning electron microscopy with elemental analysis, TEM and other.

The research has been carried out in the Laboratory of Mechanochemistry at CUT (1995-2014) in cooperation with various academic centers in Poland (e.g. at the Pedagogical and Jagiellonian Universities in Kraków, Polish Academy of Sciences in Krakow, Warsaw University of Technology, West Pomeranian University of Technology) and abroad (at the Ivanovo State University of Chemistry and Technology, National Academy of Sciences of Ukraine in Kiev).

\section{Acknowledgments}

The studies were supported by projects: Nos. PB1T09B02330, NN209145136, NN209148936, SPB70/UKR/2006/02/2006, Dec. 5673/NUkraina/2009/0, DEC-2012/05/N/ST8/03764 and POIG 1.3.2, UDA-POIG-01.03.02-12-055/12-00.

\section{References}

[1] P. Balaz, M. Achimovicova, M. Balaz, P. Billik, Z. Cherkezova-Zheleva, J.M. Criado, R. Delogu, E. Dutkova, E. Gaffet, F. Jose Gotor, R. Kumar, I. Mitov, T. Rojac, M. Senna, A. Streleckii, K. Wieczorek-Ciurowa, Chem. Soc. Rev. 42, 7571 (2013).

[2] High-Energy Ball Milling. Mechanochemical Processing of Nanopowders, Ed. M. Sopicka-Lizer, ISBN: 9781-84569-531-6 Woodhead Publ., Cambridge UK 2010.

[3] K. Wieczorek-Ciurowa, in: Ceramic Nanocomposites, Eds. R. Banerjee, I. Manna, Woodhead Publ., Cambridge UK 2013.

[4] E. Avvakumow, M. Senna, N. Kosova, Soft Mechanochemical Syntheses. A Basics for New Chemical Technologies, ISBN: 0-7923-7431-2, Kluwer Academic Publ., Massachusetts USA 2001.

[5] L. Takacs, Prog. Mater. Sci. 47, 355 (2002).

[6] C. Suryanarayana, Prog. Mater. Sci. 46, 1 (2001).

[7] K. Wieczorek-Ciurowa, K. Gamrat, Mater. Sci. Pol. 25, 219 (2007).

[8] K. Wieczorek-Ciurowa, K. Gamrat, J. Therm. Anal. Calorim. 88, 213 (2007).
[9] K. Wieczorek-Ciurowa, D. Oleszak, K. Gamrat, Rev. Adv. Mater. Sci. 18, 248 (2008).

[10] J. Rakoczy, J. Nizioł, K. Wieczorek-Ciurowa, P. Dulian, React. Kinet. Mech. Catal. 108, 81 (2013).

[11] T. Sikora, K. Wieczorek-Ciurowa, M. Kozlowski, R. Moszumański, P. Dulian, in: 14th Eur. Conf. Solid State Chemistry, Bordeaux (France), 2013, Abstracts, p. 114 .

[12] T. Sikora, M.T. Kozlowski, P. Dulian, R. Moszumański, K. Wieczorek-Ciurowa, Ceram. Ing. Trans. 32, 2095 (2013).

[13] T. Sikora, K. Wieczorek-Ciurowa, in: XII Young Res. Conf. Materials Sci. Eng., Belgrade (Serbia), 2013, Program and the Book of Abstracts, p. 12.

[14] K. Wieczorek-Ciurowa, B. Góra, M. Żala, in: XIX Int. Seminar on Physics and Chemistry of Solids, Częstochowa (Poland), 2013, Abstracts, P-26, p. 91.

[15] K. Wieczorek-Ciurowa, P. Dulian, A. Nosal, J. Domagała, J. Therm. Anal. Calorim. 101, 471 (2010).

[16] K. Wieczorek-Ciurowa, P. Dulian, W. Bąk, C. Kajtoch, Przem. Chem. 90, 1400 (2011).

[17] P. Dulian, W. Bąk, K. Wieczorek-Ciurowa, Cz. Kajtoch, Key Eng. Mater. 605, 63 (2014).

[18] P. Dulian, W. Bąk, K. Wieczorek-Ciurowa, Cz. Kajtoch, Mater. Sci.-Poland 32, (2014).

[19] W. Bak, P. Dulian, D. Sitko, B. Garbarz-Glos, C. Kajtoch, K. Wieczorek-Ciurowa, I. Smeltere, Ferroelectrics 464, 35 (2014).

[20] P. Dulian, W. Bąk, K. Wieczorek-Ciurowa, Cz. Kajtoch, Key Eng. Mater. 543, 326 (2013).

[21] P. Dulian, W. Bąk, K. Wieczorek-Ciurowa, Cz. Kajtoch, Mater. Sci.-Poland 31, 462, (2013).

[22] P. Dulian, W. Bąk, K. Wieczorek-Ciurowa, Cz. Kajtoch, T. Sikora, in Ref. [11], p. 262.

[23] K. Wieczorek-Ciurowa, A. Gomułczak, V.A. Zazhigalov, Polish J. Chem. 82, 191 (2008).

[24] J. Nizioł, J. Rakoczy, K. Wieczorek-Ciurowa, P. Dulian, in: XLV Polish Annual Conf. Catal. (OKK), Kraków (Poland), 2013, Abstracts, p. 183.

[25] V. Zazhigalov, I. Bacherikova, S. Khalameida, N. Litvin, K. Wieczorek-Ciurowa, L. Depero, A. Kowal, in: 6th World Congress on Oxidation Catalysis, Lille (France), 2009, [CD-ROM].

[26] K. Wieczorek-Ciurowa, J. Rakoczy, A. BłońskaTabero, E. Filipek, J. Nizioł, P. Dulian, Catal. Today 176, 314 (2011).

[27] A. Błońska-Tabero, E. Filipek, P. Tabero, J. Therm. Anal. Calorim. 109, 691 (2012).

[28] E. Filipek, I. Rychłowska-Himmel, A. Paczesna, J. Therm. Anal. Calorim. 109, 711 (2012).

[29] V. Zazhigalov, K. Wieczorek-Ciurowa, I. Bacherikova, L. Depero, in: GPE-EPIC 2th Int. Congress on Green Process Engineering, 2th European Process Intensification Conf., Venice (Italy), 2009 [CD-ROM]. 